\title{
Evaluation of the new capture vapourizer for aerosol mass spectrometers (AMS) through laboratory studies of inorganic species
}

\author{
W. Hu et al. \\ Correspondence to: Jose L. Jimenez (jose.jimenez@colorado.edu)
}

The copyright of individual parts of the supplement might differ from the CC BY 3.0 License. 
S1. Implications for vaporization and detection mechanisms in the AMS

It has recently been suggested that a simple model, accounting only for molecular flight through the ionizer at the vaporizer temperature, followed by electron impact ionization should completely explain SV-AMS detection (Murphy, 2016a). The high measured values of RIE $\mathrm{NH}_{4}$ are difficult to reconcile with this simple model (Jimenez et al., 2016). To explain this discrepancy, it has been proposed that $\mathrm{NH}_{4} \mathrm{NO}_{3}$ and $\left(\mathrm{NH}_{4}\right)_{2} \mathrm{SO}_{4}$ vaporize as intact salts in the AMS (Murphy, 2016a; Murphy, 2017). The present study allows some additional considerations to be made on this topic.

S1.1. Quantitative analysis of $\mathrm{RIE}_{\mathrm{NH}} 4$ when a fraction of $\mathrm{NH}_{4} \mathrm{NO}_{3}$ vaporizes as an intact salt

It has been suggested that the high $\mathrm{RIE}_{\mathrm{NH} 4}$ observed in the AMS can be explained by the vaporization of intact $\mathrm{NH}_{4} \mathrm{NO}_{3}$ molecules, followed by their ionization, and production of $\mathrm{NH}_{3}{ }^{+}$ ions with high efficiency from that process (Murphy, 2017). However, it is very difficult to reach a typical RIE $\mathrm{NH}_{4}$ of 4 based on this hypothesis with reasonable assumptions. This is even more so when considering values of $\mathrm{RIE}_{\mathrm{NH} 4} \sim 6.2$ that are often observed in AMS instruments (Salcedo et al., 2006) or values up to 14.7 on ACSM instruments (Crenn et al., 2015). This can be shown by estimating the $\mathrm{RIE}_{\mathrm{NH} 4}$ that would be observed if the detection process followed the suggestion of Murphy (2017). The following numerical assumptions are used for this calculation (and some sensitivity studies are discussed below):

a. The upper limit molar fraction of $\mathrm{NH}_{4} \mathrm{NO}_{3}(\mathrm{~g})$ estimated by Chien et al. (2010) is actually realized at the AMS vaporizer temperature of approximately $600^{\circ} \mathrm{C}$, which is much larger than the $64-92^{\circ} \mathrm{C}$ used in those experiments:

$$
\text { a. } \mathrm{NH}_{4} \mathrm{NO}_{3} \rightarrow 78 \% \mathrm{NH}_{3}(\mathrm{~g})+78 \% \mathrm{H}_{\mathrm{x}} \mathrm{NO}_{\mathrm{y}}{ }^{+}(\mathrm{g})+22 \% \mathrm{NH}_{4} \mathrm{NO}_{3}(\mathrm{~g})
$$

b. The ionization efficiency of each species is approximately proportional to its molecular weight (Jimenez et al., 2003).

c. All the species have the same average translational temperature (as implicitly assumed in Murphy et al. 2016a, 2016b), and thus that their flights times scale as $\sqrt{M W}$.

d. $1 / 2$ of the $\mathrm{H}_{\mathrm{x}} \mathrm{NO}_{\mathrm{y}}(\mathrm{g})$ is $\mathrm{NO}_{2}(\mathrm{~g})$ and the other $1 / 2$ is $\mathrm{HNO}_{3}(\mathrm{~g})$.

e. The molar fragmentation fraction for molecular $\mathrm{NH}_{4} \mathrm{NO}_{3}{ }^{+}$favors $\mathrm{NH}_{3}{ }^{+}$more than proportionally to its mass fraction in the parent ion, as suggested by Murphy (2017). E.g.: 


$$
\mathrm{NH}_{4} \mathrm{NO}_{3}{ }^{+} \rightarrow 50 \% \mathrm{NH}_{3}{ }^{+}+50 \% \mathrm{HNO}_{3}(\mathrm{~g})+50 \% \mathrm{NH}_{3}(\mathrm{~g})+50 \% \mathrm{HNO}_{3}{ }^{+}
$$

With those assumptions $\mathrm{RIE}_{\mathrm{NH} 4} \sim$ 1.1. If one assumes in (d) $100 \%$ of either $\mathrm{NO}_{2}(\mathrm{~g})$ or $\mathrm{HNO}_{3}(\mathrm{~g})$ for $\mathrm{H}_{\mathrm{x}} \mathrm{NO}_{\mathrm{y}}{ }^{+}(\mathrm{g})$, then $\mathrm{RIE}_{\mathrm{NH} 4} \sim 1.05-1.12$ can be obtained. If one assumes in (e) that the fragmentation of $\mathrm{NH}_{4} \mathrm{NO}_{3}{ }^{+}$yields $75 \% \mathrm{NH}_{\mathrm{x}}{ }^{+}, \mathrm{RIE}_{\mathrm{NH} 4}=1.5$ (if one assumes $100 \% \mathrm{NH}_{\mathrm{x}}{ }^{+}$, then $\mathrm{RIE}_{\mathrm{NH} 4}=2.1$ ). Thus even with aggressive assumptions, the hypothesis is not consistent with the observed RIE $\mathrm{NH}_{4}$ values of 4-14. It is very likely that the $\mathrm{NH}_{4} \mathrm{NO}_{3}$ (g) fraction under (a) is much lower in the AMS (due to the $520^{\circ} \mathrm{C}$ higher $T_{v}$ ), probably near zero. If we assume a value of $5 \%$, and the rest of the default assumptions above, then $\mathrm{RIE}_{\mathrm{NH} 4} \sim 0.7$. Thus it seems very difficult to quantitatively explain the observed $\mathrm{RIE}_{\mathrm{NH} 4}$ with the Murphy (2017) hypothesis with reasonable assumptions.

For reference, Figure $\mathrm{S} 4$ shows the estimated RIE $\mathrm{NH}_{4}$ estimated in this way as a function of the two key parameters. To obtain values of $\mathrm{RIE}_{\mathrm{NH} 4}=4$ and larger, one needs to assume that a very large fraction of $\mathrm{NH}_{4} \mathrm{NO}_{3}$ vaporizes as $\mathrm{NH}_{4} \mathrm{NO}_{3}(\mathrm{~g}$ ) (far higher than the upper limit reported at $80^{\circ} \mathrm{C}$ ), AND that the fragmentation of $\mathrm{NH}_{4} \mathrm{NO}_{3}{ }^{+}$very strongly favors $\mathrm{NH}_{\mathrm{x}}{ }^{+}$ions. Importantly, the high vaporized fraction of $\mathrm{NH}_{4} \mathrm{NO}_{3}(\mathrm{~g})$ would also need to be achieved for mixed ambient particles with high organic and low $\mathrm{NH}_{4} \mathrm{NO}_{3}$ fractions, in order for this hypothesis to be consistent with ambient observations.

S1.2. Other evidence against the vaporization of a major fraction of $\mathrm{NH}_{4} \mathrm{NO}_{3}$ and $\left(\mathrm{NH}_{4}\right)_{2} \mathrm{SO}_{4}$ as intact salts in the AMS

The hypothesis of dominant vaporization of intact salts is also inconsistent with other published pieces of evidence discussed before, including:

(a) There is evidence from evaporation of ambient particles in thermal denuders that ammonia can evaporate from ammonium/nitrate/sulfate particles before the sulfate does, leaving the acids behind (Huffman et al., 2009, figure reproduced below as Fig. S5). It is thus plausible that the same process occurs in the AMS vaporizer, leading to very different fragmentation behavior of $\mathrm{NH}_{3}(\mathrm{~g})$ and the anions in the detection process (Fig. 4 in the main text).

(b) The constancy of the fragmentation pattern of $\mathrm{NH}_{3}(\mathrm{~g})$ across vaporizers and temperatures (compared to very large simultaneous changes for the associated anions), and the high similarity 
with the NIST database pattern, also support separate vaporization of $\mathrm{NH}_{3}(\mathrm{~g})$, as discussed in the main text.

(c) Single particle detection timescales for different ion fragments of the same species can provide insight into vaporization and ionization processes. The timescale of single particle signals of $\mathrm{NH}_{4}{ }^{+}$and the anion fragments is very different for both ammonium nitrate and ammonium sulfate (Jimenez et al., 2016). The fact that dominant cations and anions have different detection timescales indicates that they do not originate from the same species in the vapor phase.

(d) Ambient and laboratory data for mixed particles show that the sensitivity of ammonium relative to sulfate and nitrate is very constant (within 5\%) over very wide changes in fractional composition, and also in the presence of large and variable amounts of internally-mixed organic species (Jimenez et al., 2016). If a very large fraction of the $\mathrm{NH}_{\mathrm{x}}{ }^{+}$ions arose from the ionization of intact salt molecules and their subsequent fragmentation, it seems very unlikely that by coincidence the relative sensitivities to ammonium, nitrate, and sulfate would stay constant, despite order-of-magnitude changes in the relative composition of the vaporized salts, including likely vaporization of mixed salts. This evidence is especially important for ambient particles, which are often dominated by organic species.

(e) The vaporization event lengths for single particles in the SV do not support the hypothesis (implicit in the calculations suggested by Murphy, 2017) that all species vaporize with the same temperature (either $T_{v}$ or a lower value common for all vaporized species) (Jimenez et al., 2016). This is also consistent with the results of Saleh et al. (2017), who show that the expected vaporization temperatures in the AMS are lower than $T_{v}$ due to evaporative cooling.

\section{S1.3. Evidence against significant mass discrimination in the AMS}

It has been suggested (Murphy, 2017) that "A mass-dependent sensitivity for the AMS spectrometer and detector might explain part of the high RIE [...]," although the same author stated that a large amount of mass discrimination in the AMS is unlikely (Murphy, 2016b). If the $\mathrm{NH}_{\mathrm{x}}{ }^{+}$ions formed from ammonium were detected more efficiently than the $\mathrm{NO}_{\mathrm{x}}{ }^{+}$(and $\mathrm{SO}_{\mathrm{x}}{ }^{+}$) ions, that effect could contribute to a larger-than-expected $\mathrm{RIE}_{\mathrm{NH} 4}$. Mass discrimination 
could arise for two reasons: (a) ions of lower $\mathrm{m} / \mathrm{z}$ could be transmitted by the AMS ion optics and mass spectrometer and onto the microchannel plate (MCP) detector more efficiently; or (b) the response of the MCP detector could be substantially larger for ions of lower $\mathrm{m} / \mathrm{z}$. The first item can be evaluated by comparing the fragmentation patterns of $\mathrm{N}_{2}$ and $\mathrm{O}_{2}$ from air vs. those in the NIST mass spectral database (Fig. S6, left). Those patterns are similar on average, also consistent with measured vs. NIST $\mathrm{C}^{+} / \mathrm{CO}_{2}{ }^{+}$ratios from $\mathrm{CO}_{2}(\mathrm{~g})$ (not shown). This indicates the lack of a substantially enhanced transmission favoring small $\mathrm{m} / \mathrm{z}$ in the AMS. Importantly, the mass ranges involved in this comparison are the relevant ones for most of the ions formed from $\mathrm{NH}_{4} \mathrm{NO}_{3}$. For the second item, Fig. S6 (right) shows a typical result for the measured response of the MCP vs $m / z$ as routinely acquired during the AMS threshold-setting process. We estimate that MCP response to $\mathrm{NH}_{\mathrm{x}}{ }^{+}$ions is $\sim 5 \%$ (10\%) larger than for $\mathrm{NO}_{\mathrm{x}}{ }^{+}\left(\mathrm{SO}_{\mathrm{x}}{ }^{+}\right)$ions, and thus it is a very small effect that can only contribute little to the high observed RIE $\mathrm{NH}_{4}$.

\section{S1.4. Evidence against a strong effect of mass spectrometer tuning on RIE $\mathrm{NH}_{4}$}

It is of interest to investigate whether a high sensitivity of AMS RIEs to mass spectrometer or MCP detector tuning parameters could provide an alternative explanation of the observed $\mathrm{RIE}_{\mathrm{NH} 4}$ values. The most sensitive and important tuning voltage in the AMS is the vaporizer bias, which is tuned within a narrow signal maximum of $\sim 1 \mathrm{~V}$. Figure S7 shows the variation of $\mathrm{RIE}_{\mathrm{NH} 4}$ vs. vaporizer bias voltage while sampling pure $\mathrm{NH}_{4} \mathrm{NO}_{3}$. $\mathrm{RIE}_{\mathrm{NH} 4}$ varies only by $2 \%$ over the optimum region, indicating that instrument tuning is unlikely to lead to substantial variations of $\mathrm{RIE}_{\mathrm{NH} 4}$.

The MCP detector voltage is always set high enough so that the overwhelming majority of the single ions are detected above the noise level, and it is not changed during instrument operation (other than to compensate for its degradation over time). Higher microchannel plate voltages would result on the same relative signals but shorter plate lifetime (and potentially saturation of the data acquisition card or MCP at very high instantaneous currents), while lower voltages would result in a well-known bias against weak signals (e.g. Hings et al., 2007). Thus, reporting RIE values vs. MCP voltage is not of high interest, as only one method for setting this voltage is used in practice.

\section{S1.5. Summary}


We conclude that the simple model of molecular flight and ionization proposed by Murphy (2016a) has difficulty explaining the observed high RIE $_{\mathrm{NH}}$ in the SV-AMS. While the processes included in the model are definitely occurring during AMS detection, this implies that other processes not accounted for in the model are also important. Evidence presented in this paper also suggests that detection in the CV-AMS detection may be closer to the Murphy (2016a) model, in particular since the observed $T_{v}$-dependence of some signals follows a similar trend as predicted by the model, vs. major differences for the SV-AMS (Jimenez et al., 2016). The key differences between the $\mathrm{CV}$ and $\mathrm{SV}$ detection are the suppression of particle bounce in the $\mathrm{CV}$ and the likelihood that vaporized molecules will undergo many collisions with the CV (vs. $\sim 1$ in the SV) and thus reach $T_{v}$. This suggests that those two processes may play an important role in explaining the discrepancies between the Murphy (2016a) model and experimental SV-AMS data: (a) particle bounce followed by slower evaporation from other surfaces in the detection region and/or (b) vaporization at temperatures lower than $T_{v}$, as expected from evaporative cooling (Saleh et al., 2017) and the lack of sufficient collisions between vaporized gas molecules and the SV for thermalization (Jimenez et al., 2016). However, we note that the high RIE $\mathrm{NH}_{4}$ in the CV-AMS still appears inconsistent with the simplified model. Further research, likely including the application of soft-ionization methods, is necessary to further clarify AMS detection details. 


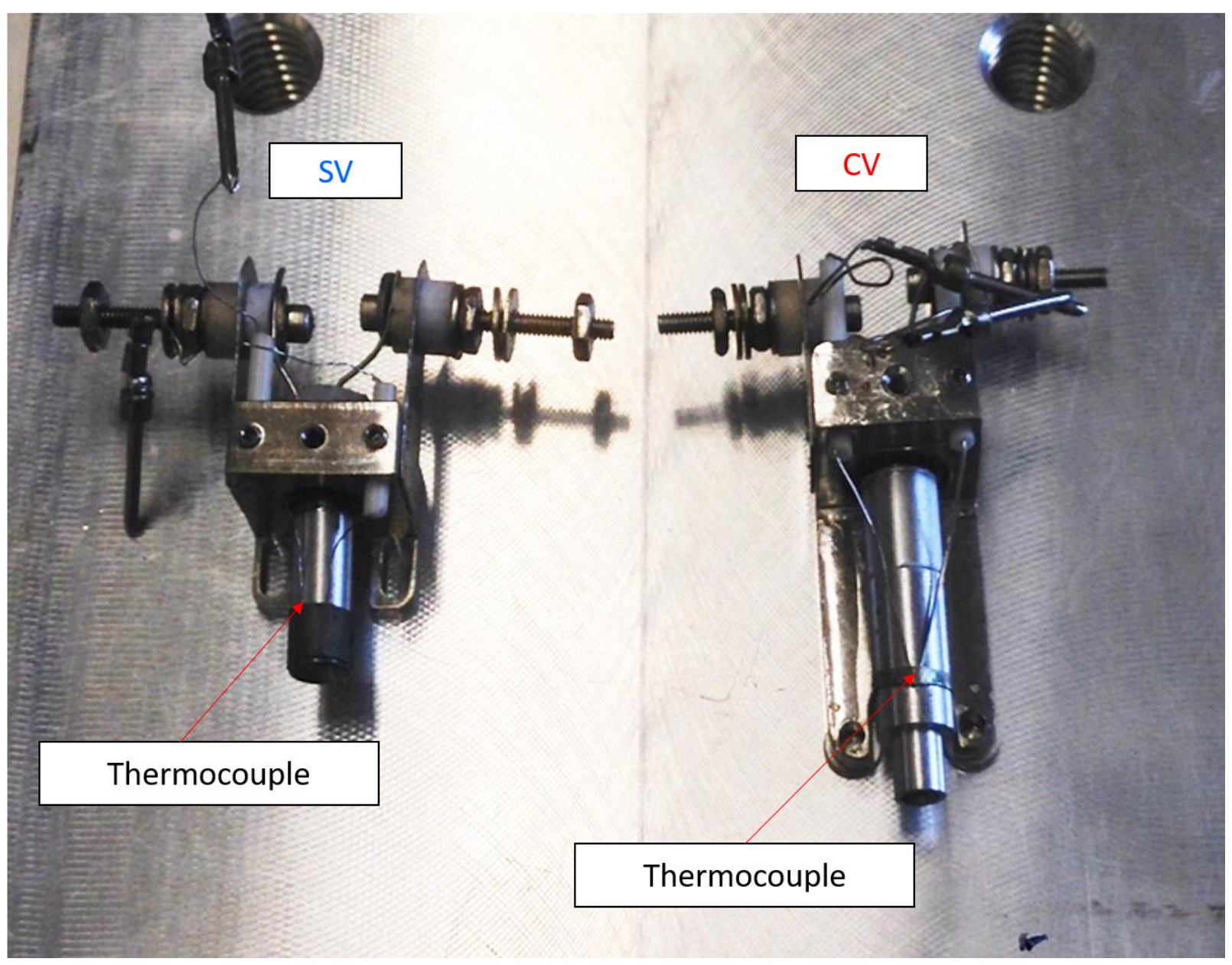

Figure S1 Picture of a standard vaporizer (SV, left) and a capture vaporizer (CV, right). 


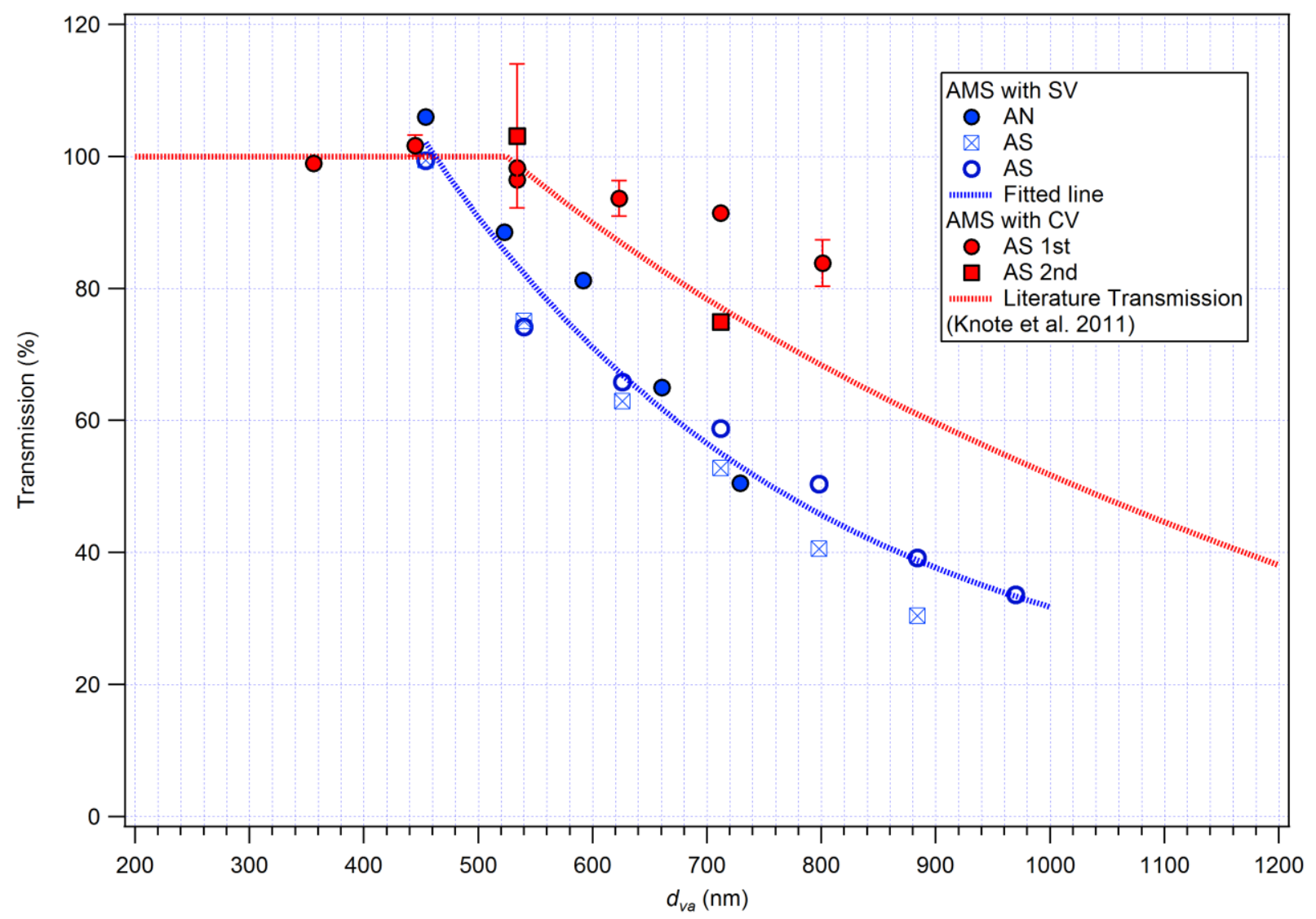

Figure S2 Lens transmission curve measured in this study for the AMSs with CV and SV. For $d_{\text {va }}$ below $460 \mathrm{~nm}$ in SV AMS and $550 \mathrm{~nm}$ in CV AMS, no lens transmission correction was needed $\left(E_{L}=1\right)$. In the experiments shown in this study, only $\mathrm{NaNO}_{3}$ needs a transition loss correction for its high $d_{\mathrm{va}}(=680 \mathrm{~nm})$. During the experiment, an underperforming lens (that has since been replaced) was used in AMS with SV, thus showed a larger particle loss than the AMS

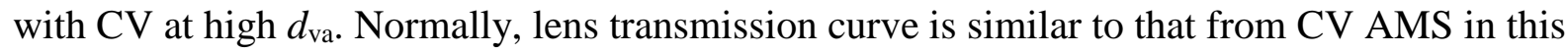
study, however individual AMS lens transmission calibrations are always recommended. 

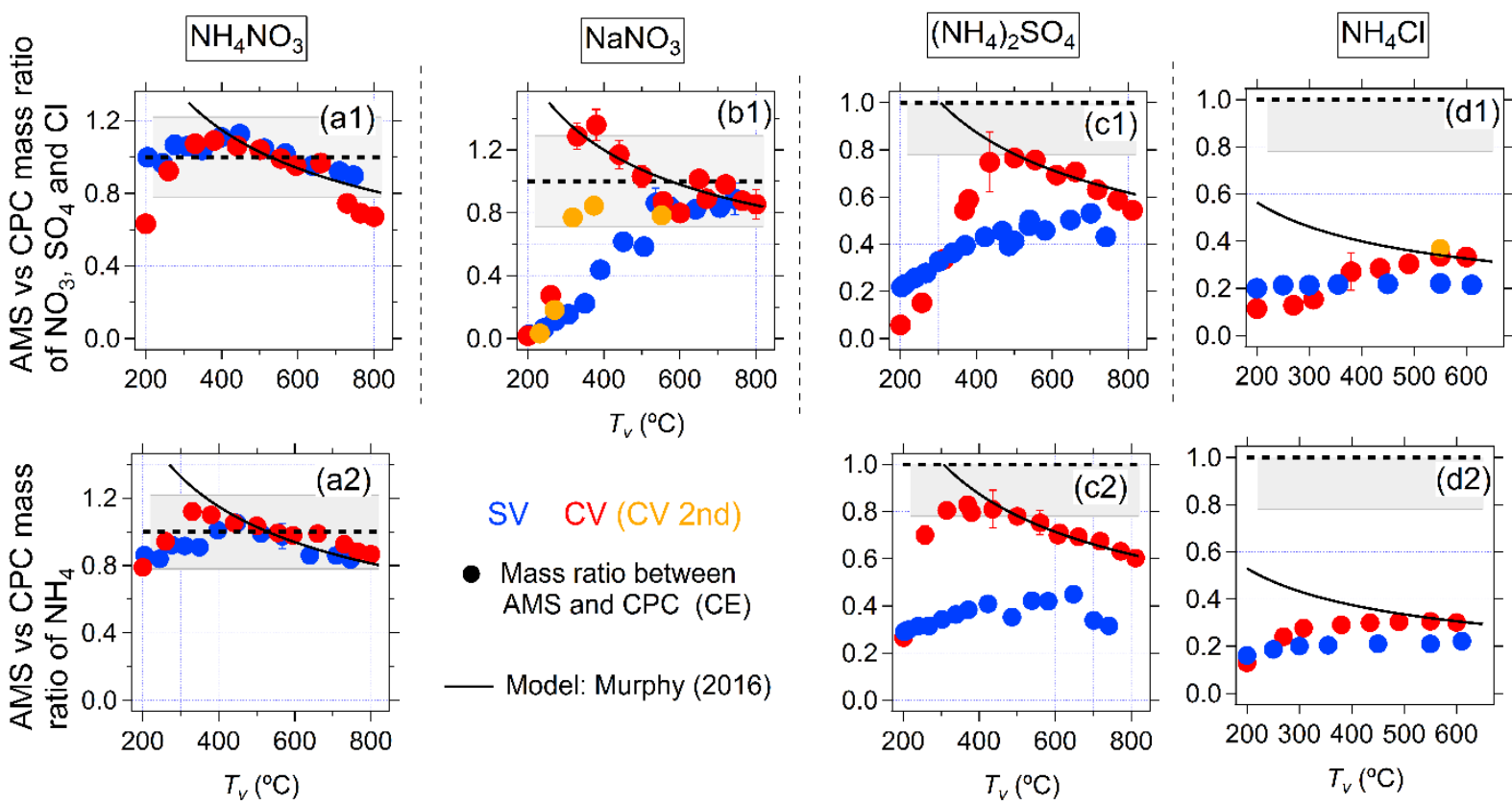

Figure S3 Ratios of mass concentration between AMS and CPC measurements (CE) from four inorganic species (dried monodisperse particles) of (a) $300 \mathrm{~nm} \mathrm{NH}_{4} \mathrm{NO}_{3}$; (b) $250 \mathrm{~nm}\left(\mathrm{NH}_{4}\right)_{2} \mathrm{SO}_{4}$; (c) $300 \mathrm{~nm} \mathrm{NaNO}$; (d) $300 \mathrm{~nm} \mathrm{NH} 4 \mathrm{Cl}$. The black line was calculated based the relationship described in Eq. (2) of Murphy (2016a), which predicts that the measured AMS intensity should follow $1 / \sqrt{T_{v}}$ dependence as $T_{v}$ is varied. The black curves have been arbitrarily scaled vertically to match the red $\mathrm{CV}$ point around $600{ }^{\circ} \mathrm{C}$. A dependence for $\mathrm{CV}$ consistent with the theory appears to be observed for several species at the higher end of the $T_{v}$ profiles. Gray shading represents the estimated uncertainty range (see Fig. 9 in the main text and associated discussion for details). 


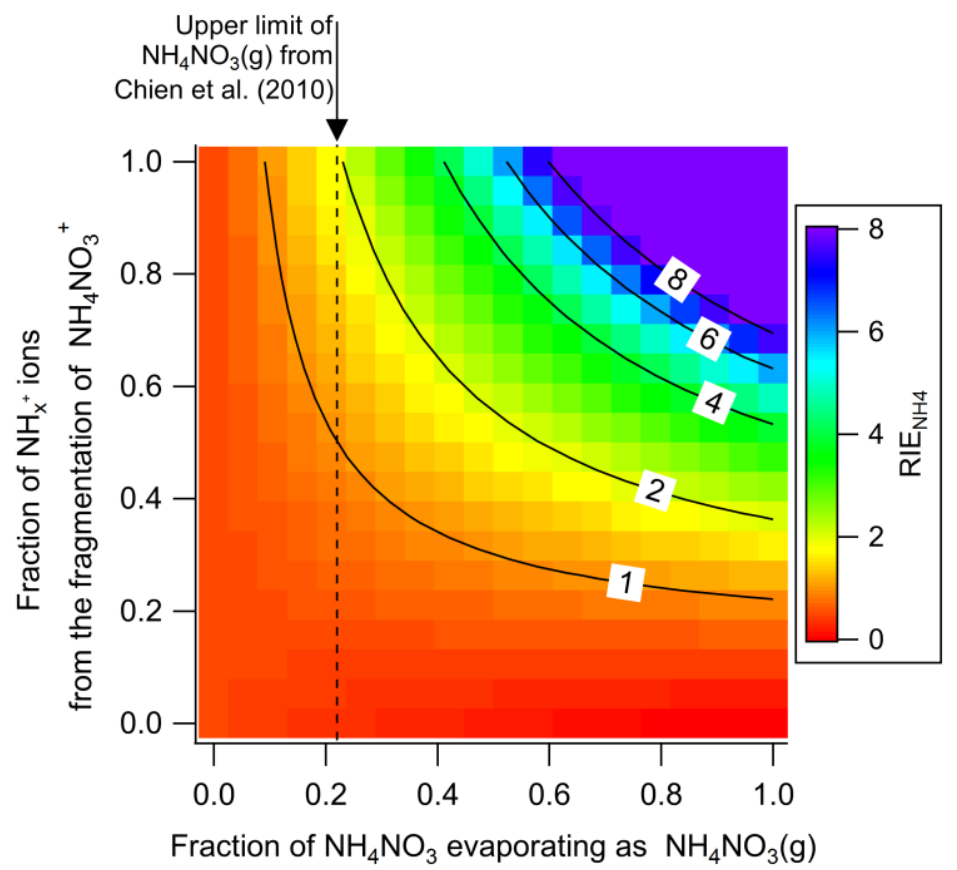

Figure S4 Estimated $\mathrm{RIE}_{\mathrm{NH}}$ as a function of the assumed fraction of $\mathrm{NH}_{4} \mathrm{NO}_{3}$ vaporizing as $\mathrm{NH}_{4} \mathrm{NO}_{3}(\mathrm{~g})$, and the fraction of $\mathrm{NH}_{\mathrm{x}}{ }^{+}$ions formed from the fragmentation of $\mathrm{NH}_{4} \mathrm{NO}_{3}{ }^{+}$. Also marked is the upper limit fraction of $\mathrm{NH}_{4} \mathrm{NO}_{3}(\mathrm{~g})$ evaporated at $\sim 80^{\circ} \mathrm{C}$ (Chien et al., 2010) 

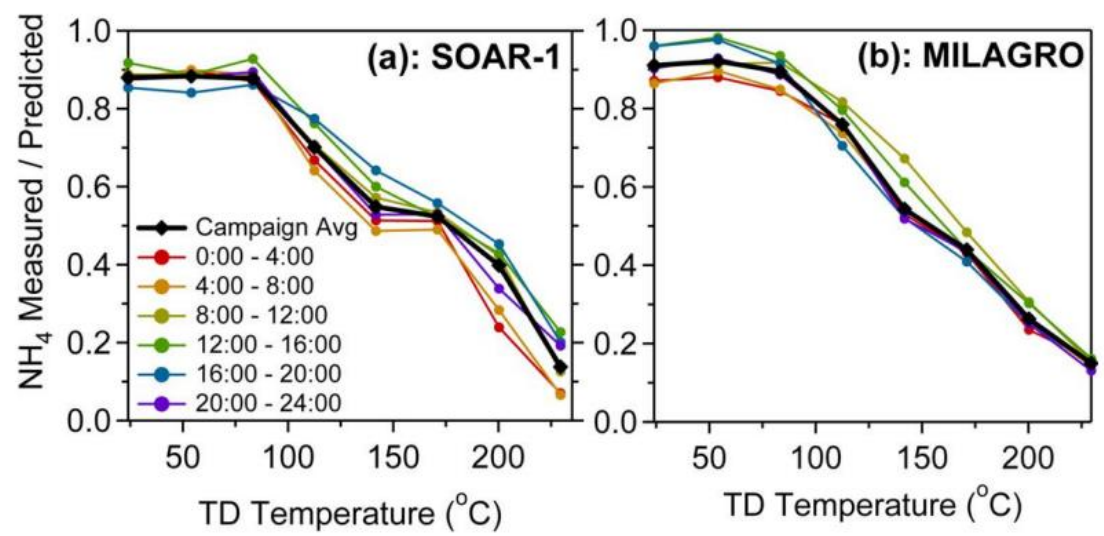

Fig. 5. $\mathrm{NH}_{4}^{+}$measured/predicted ratio (Eq. 1) shown as a function of TD temperature for averages of the total campaign (solid black line) and for six 4-h daily time blocks for (colored lines). Relative acidity increases as measured/predicted ratio decreases. (a) SOAR1 and (b) MILAGRO.

Figure S5 This figure is reproduced from figure in Huffman et al. (2009) 

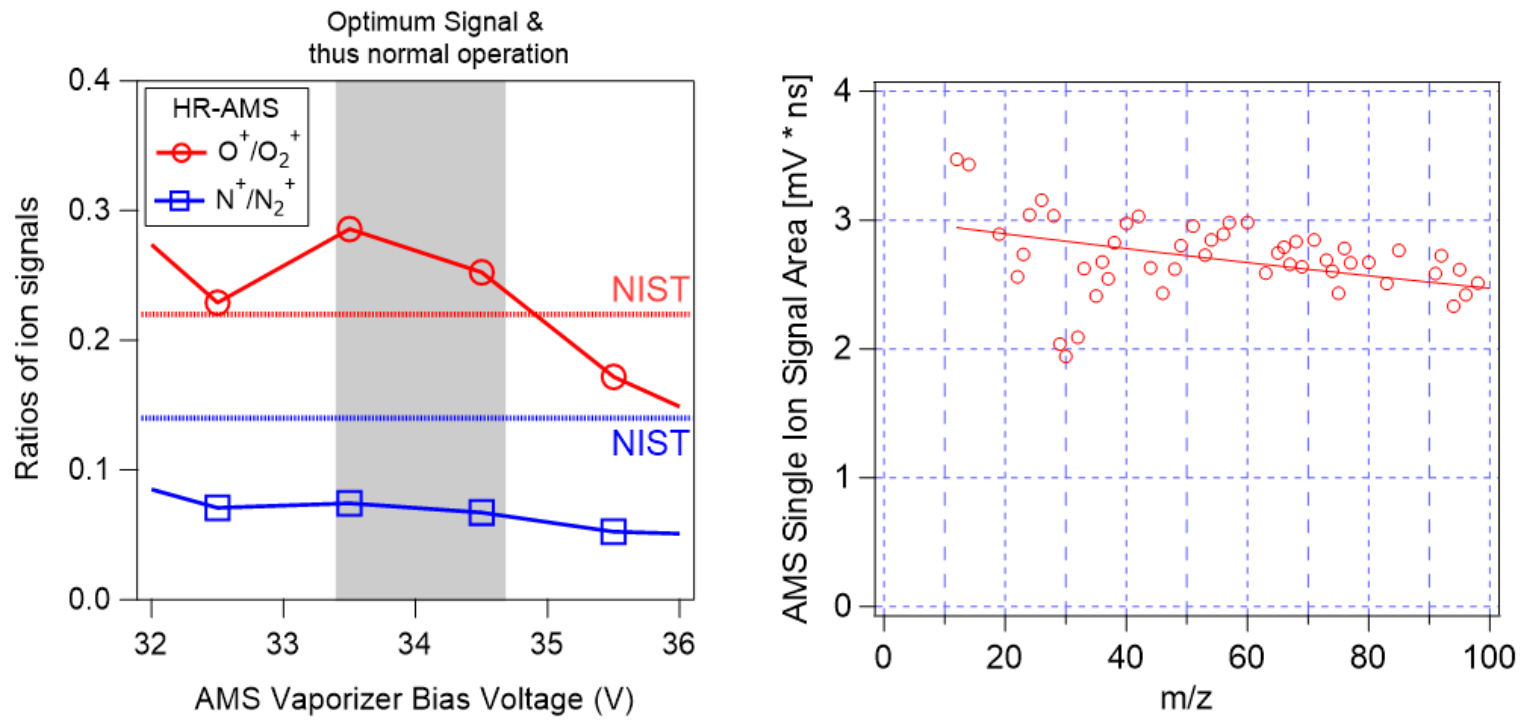

Figure S6 Left: comparison of the fragmentation patterns of $\mathrm{O}_{2}$ and $\mathrm{N}_{2}$ in the HR-AMS to those in the NIST database. Right: measured response of the AMS microchannel plate to single ions as a function of $\mathrm{m} / \mathrm{z}$. Only $\mathrm{m} / \mathrm{z}$ at which the signal is dominated by individual ions events, based on ion detection frequencies while analyzing the AMS background signal, are shown. 


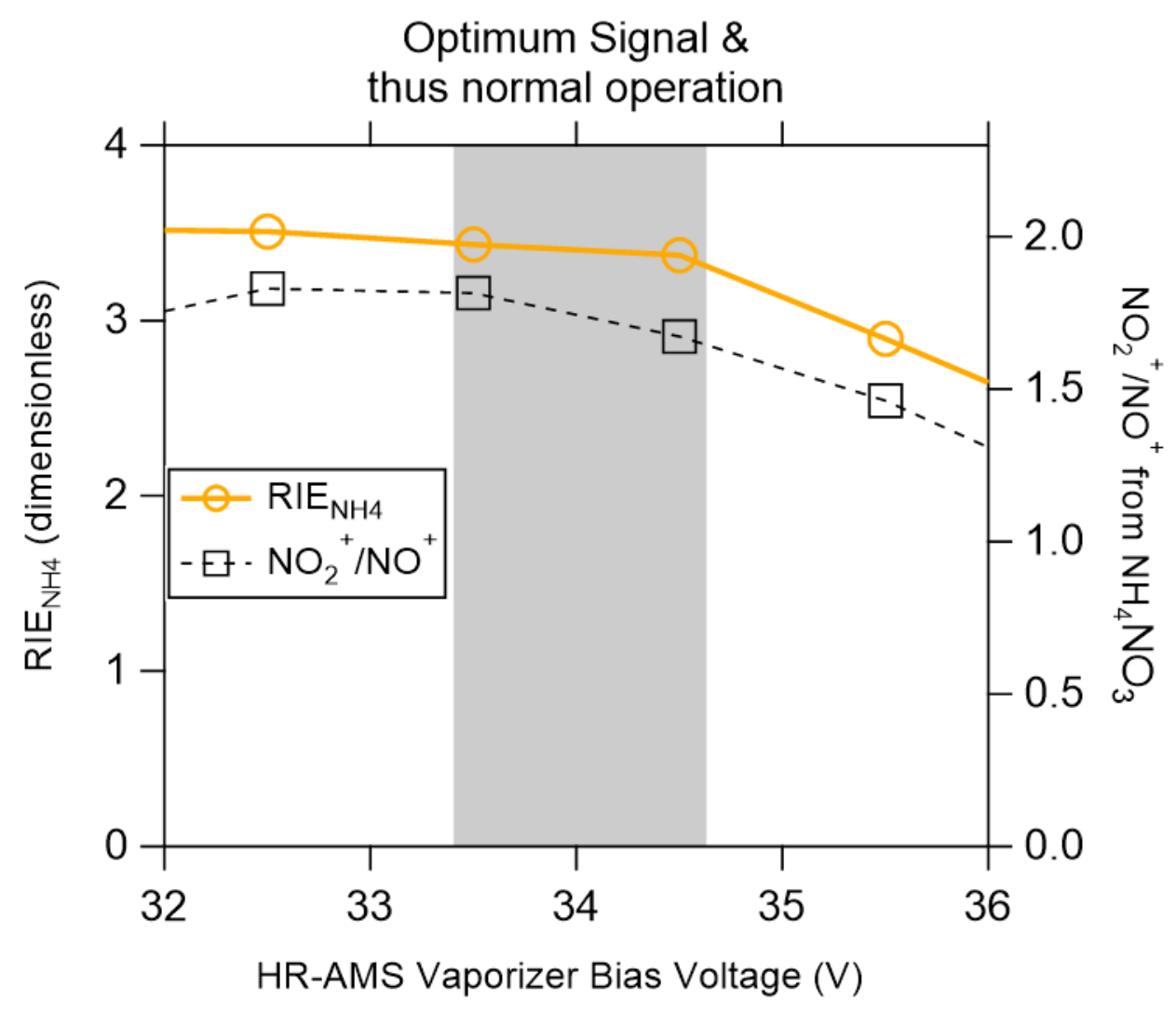

Figure S7 Variation of $\mathrm{RIE}_{\mathrm{NH} 4}$ and the $\mathrm{NO}_{2}{ }^{+} / \mathrm{NO}^{+}$ratio as a function of HR-AMS vaporizer bias voltage while sampling pure $\mathrm{NH}_{4} \mathrm{NO}_{3}$ particles. Only $\sim 2 \%$ variation is observed for $\mathrm{RIE}_{\mathrm{NH}}$ across the optimum tuning region, while $\sim 8 \%$ variation is observed for the $\mathrm{NO}_{2}{ }^{+} / \mathrm{NO}^{+}$ratio. 


\section{References:}

Chien, W.-M., Chandra, D., Lau, K. H., Hildenbrand, D. L., and Helmy, A. M.: The vaporization of NH4NO3, The Journal of Chemical Thermodynamics, 42, 846-851, doi:10.1016/j.jct.2010.01.012, 2010.

Crenn, V., Sciare, J., Croteau, P. L., Verlhac, S., Fröhlich, R., Belis, C. A., Aas, W., Äijälä, M., Alastuey, A., Artiñano, B., Baisnée, D., Bonnaire, N., Bressi, M., Canagaratna, M., Canonaco, F., Carbone, C., Cavalli, F., Coz, E., Cubison, M. J., Esser-Gietl, J. K., Green, D. C., Gros, V., Heikkinen, L., Herrmann, H., Lunder, C., Minguillón, M. C., Močnik, G., O'Dowd, C. D., Ovadnevaite, J., Petit, J. E., Petralia, E., Poulain, L., Priestman, M., Riffault, V., Ripoll, A., Sarda-Estève, R., Slowik, J. G., Setyan, A., Wiedensohler, A., Baltensperger, U., Prévôt, A. S. H., Jayne, J. T., and Favez, O.: ACTRIS ACSM intercomparison - Part 1: Reproducibility of concentration and fragment results from 13 individual Quadrupole Aerosol Chemical Speciation Monitors (Q-ACSM) and consistency with co-located instruments, Atmos. Meas. Tech., 8, 5063-5087, 10.5194/amt-8-5063-2015, 2015.

Hings, S. S., Walter, S., Schneider, J., Borrmann, S., and Drewnick, F.: Comparison of a quadrupole and a time-of-flight aerosol mass spectrometer during the Feldberg aerosol characterization experiment 2004, Aerosol Sci Tech, 41, 679-691, Doi 10.1080/02786820701408483, 2007.

Huffman, J. A., Docherty, K. S., Aiken, A. C., Cubison, M. J., Ulbrich, I. M., DeCarlo, P. F., Sueper, D., Jayne, J. T., Worsnop, D. R., Ziemann, P. J., and Jimenez, J. L.: Chemically-resolved aerosol volatility measurements from two megacity field studies, Atmos Chem Phys, 9, 7161-7182, 2009.

Jimenez, J. L., Jayne, J. T., Shi, Q., Kolb, C. E., Worsnop, D. R., Yourshaw, I., Seinfeld, J. H., Flagan, R. C., Zhang, X. F., Smith, K. A., Morris, J. W., and Davidovits, P.: Ambient aerosol sampling using the Aerodyne Aerosol Mass Spectrometer, J Geophys Res-Atmos, 108, 8425, Doi 10.1029/2001jd001213, 2003.

Jimenez, J. L., Canagaratna, M. R., Drewnick, F., Allan, J. D., Alfarra, M. R., Middlebrook, A. M., Slowik, J. G., Zhang, Q., Coe, H., Jayne, J. T., and Worsnop, D. R.: Comment on "The effects of molecular weight and thermal decomposition on the sensitivity of a thermal desorption aerosol mass spectrometer", Aerosol Sci Tech, 50, i-xv, 10.1080/02786826.2016.1205728, 2016.

Murphy, D.: Interactive comment on "Evaluation of the new capture vaporizer for Aerosol Mass Spectrometers (AMS) through laboratory studies of inorganic species" by Weiwei Hu et al., Atmos. Meas. Tech. Discuss., http://www.atmos-meas-tech-discuss.net/amt-2016-337/, 2017.

Murphy, D. M.: The effects of molecular weight and thermal decomposition on the sensitivity of a thermal desorption aerosol mass spectrometer, Aerosol Sci Tech, 50, 118-125, 10.1080/02786826.2015.1136403, 2016a.

Murphy, D. M.: Reply to "Comment on the effects of molecular weight and thermal decomposition on the sensitivity of a thermal desorption aerosol mass spectrometer" by Jimenez et al, Aerosol Sci Tech, 1-7, 10.1080/02786826.2016.1254347, 2016b.

Salcedo, D., Onasch, T. B., Dzepina, K., Canagaratna, M. R., Zhang, Q., Huffman, J. A., DeCarlo, P. F., Jayne, J. T., Mortimer, P., Worsnop, D. R., Kolb, C. E., Johnson, K. S., Zuberi, B., Marr, L. C., Volkamer, R., Molina, L. T., Molina, M. J., Cardenas, B., Bernabe, R. M., Marquez, C., Gaffney, J. S., Marley, N. A., Laskin, A., Shutthanandan, V., Xie, Y., Brune, W., Lesher, R., Shirley, T., and Jimenez, J. L.: Characterization of ambient aerosols in Mexico City during the MCMA-2003 campaign with Aerosol Mass Spectrometry: results from the CENICA Supersite, Atmos Chem Phys, 6, 925-946, 2006.

Saleh, R., Robinson, E. S., Ahern, A. T., and Donahue, N. M.: Evaporation rate of particles in the vaporizer of the Aerodyne aerosol mass spectrometer, Aerosol Sci Tech, 1-8, 10.1080/02786826.2016.1271109, 2017. 